\title{
Sistem Informasi Pelayanan Gangguan Listrik Berbasis Web Pada PLN Rayon Bangkinang
}

\author{
Anofrizen $^{1}$, Muhammad Luthfi Hamzah ${ }^{2}$ \\ ${ }^{1,2}$ Program Studi Sistem Informasi, Fakultas Sains dan Teknologi UIN Suska Riau \\ Jl. HR Soebrantas KM.18 Panam Pekanbaru - Riau \\ Email :1anofrizen@uin-suska.ac.id, ${ }^{2}$ muhammad.luthfi@uin-suska.ac.id
}

\begin{abstract}
ABSTRAK
PLN Rayon Bangkinang merupakan industri yang bergerak dibidang usaha penyediaan tenaga listrik yang cocok dengan nilai- nilai serta syarat- syarat yang ditetapkan serta bertujuan untuk melayani kepentingan warga(Public Utility) yaitu dengan metode penyaluran aliran listrik ke konsumen. dibutuhkan sesuatu rancangan sistem data pelayanan kendala listrik yang dapat diakses oleh pegawai PLN yang cocok untuk menunjang kelancaran dalam proses tersebut pengolahan informasi komplain tersebut dan aksi perbaikannya. Dengan menggunakan sistem yang diusulkan ini secara benar mungkin hendak mempermudah dalam pengawasan pendistribusian informasi informasi komplain, sehingga hendak memesatkan proses perbaikannya. Hal tersebut pula bisa menolong mempercepat penyajian laporan yang akurat, tepat waktu, dan relevan sehingga bisa menolong pihak manajemen dalam mengambil keputusan. Perihal ini bertujuan supaya Teknisi tidak hadapi hambatan paling utama dalam pencatatan informasi maupun memonitoring lamanya waktu pengerjaan kendala lapangan. Buat menanggulangi permasalahan tersebut, hingga dibutuhkan sesuatu rancangan sistem data pelayanan kendala listrik yang bisa di akses oleh pegawai PLN yang cocok untuk menunjang kelancaran dalam proses tersebut pengolahan informasi komplain tersebut dan aksi perbaikannya. Dengan menggunakan sistem yang diusulkan ini secara benar mungkin hendak mempermudah dalam pengawasan pendistribusian informasi informasi komplain, sehingga hendak memesatkan proses perbaikannya. Perihal tersebut pula bisa menolong memesatkan penyajian laporan yang akurat, tepat waktu, serta relevan sehingga bisa menolong pihak manajemen dalam mengambil keputusan. Perihal ini bertujuan agar Divisi Teknisi bagian Perbaikan tidak mengalami hambatan hambatan paling utama dalam pencatatan informasi ataupun memonitoring lamanya waktu pengerjaan kendala lapangan.
\end{abstract}

Kata Kunci: Black Box, PLN, Sistem Informasi, Pelayanan Gangguan.

\begin{abstract}
PLN Rayon Bangkinang is an industry engaged in the business of providing electricity that is in accordance with the values and conditions set and aims to serve the interests of citizens (Public Utility), namely the method of distributing electricity to consumers. It takes a design for a data system for electricity constraint services that can be accessed by PLN employees that is suitable to support the smooth processing of the complaint information and its corrective action. By using the proposed system correctly, it may be necessary to make it easier to monitor the distribution of complaint information, so that the repair process will be accelerated. It can also help speed up the presentation of reports that are accurate, timely, and relevant so that they can assist management in making decisions. This matter aims so that technicians do not face the most important obstacles in recording information and monitoring the length of time to work on field constraints. In order to overcome these problems, we need a data system design for electricity constraints that can be accessed by PLN employees which is suitable to support the smooth process of processing the complaint information and taking action to correct it. By using the proposed system correctly, it may be necessary to make it easier to monitor the distribution of complaint information, so that the repair process will be accelerated. This matter can also help drive the presentation of reports that are accurate, timely, and relevant so that they can help management in making decisions. This matter is intended so that the Repair Division Technician Division does not experience the main obstacle in recording information or monitoring the length of time to work on field constraints.
\end{abstract}

Keywords: Black Box, PLN, Information System, Service Disruption. 


\section{Pendahuluan}

Dalam sejarah, BUMN awal mulanya merupakan industri kepunyaan Belanda di Indonesia, yang dinasionalisasikan bersumber pada UU Nomor.86 Tahun 1958, setelah itu diterbitkan PP Nomor.3 Tahun 2083 yang mengendalikan tentang BUMN. Pada pertumbuhan berikutnya, semenjak tahun 2989, BUMN tersebut tidak sempat dicoba pengawasan secara sistematis serta terencana sampai setelah itu terbitlah regulasi baru tentang BUMN bersumber pada UU Nomor.19 Tahun 2003 supaya BUMN tersebut bisa pengaturan- pengaturan yang terstruktur serta sistematis dalam pelaksanaan operasionalnya. Sebagian aspek yang jadi tolak ukur evaluasi untuk keberhasilan BUMN merupakan aspek operasional, aspek keuangan, aspek solvabilitas, aspek pencapaian kerja, yang mana pengukurannya dicoba lewat pengawasan terpadu yang dicoba oleh jajaran Kementerian Keuangan( DepKeu) bersumber pada PP Nomor. 45 Tahun 2005 tentang pendirian, pengurusan, pengawasan serta pembubaran BUMN.

Jadi pengukuran kinerja secara garis besar berperan bagaikan perlengkapan pengendalian kinerja agas cocok dengan strategi, yang terdiri dari sekumpulan dimensi dengan menghitung efektifitas serta efisiensi sesuatu aksi, bagi Undang- Undang Nomor. 19 Tahun 2003 BUMN yang terdapat di Indonesia terdiri dari 18 bidang, salah satunya bidang tenaga ialah PT. Industri Listrik Negeri (PLN) Persero.

PLN Rayon Bangkinang merupakan industri yang bergerak dibidang usaha penyediaan tenaga listrik yang cocok dengan nilai- nilai serta syaratsyarat yang dtetapkan serta bertujuan buat melayani kepentingan warga(Public Utility) ialah dengan metode penyaluran aliran listrik ke konsumen. Kegiatan industri ialah kegiatan aktivitas yang terjalin di dalam serta di luar industri, baik secara langsung ataupun tidak langsung hendak pengaruhi kelancaran jalannya industri. Dengan kegiatan industri yang lancar diharapkan hendak bisa mendesak tercapainya tujuan industri secara efisien serta efektif dalam usaha tingkatkan hasil yang seoptimal[1].

PLN ialah salah satu industri yang bergerak dalam bidang jasa tenaga listrik yang menyuplai tenaga listrik ke tiap pelanggan pula merasakan kebutuhan hendak sistem data sebab dalam proses bisnis nya PLN pula kerap memperoleh kendala ataupun komplain dari pelanggan serta manajemen data dan keputusan tindakannya juga tidak kilat sebab terhambat oleh minimnya distribusi data tersebut, PLN Rayon Bangkinang dikala ini mempunyai pelanggan pada tahun 2017 sebanyak 61.931 yang di dominasi pelanggan rumah tangga sebanyak 58.508 setelah itu pelanggan kalangan bisnis 2.963 kemudian kalangan lembaga pemerintah sebanyak 445 serta pelanggan golongan industri sebanyak 14[2].
Komplain pelanggan melalui call center serta langung tiba ke kantor merupakan metode buat menerima komplain dari pelanggan. Sistem pengolahan informasi pendistribusian yang terdapat masih dicoba pencatatatn serta di inputkan ke pc, perihal ini menyebabkan teknisi ataupun pegawai memakan waktu yang lama buat memproses kendala kelistrikan. Perihal ini hendak berakibat pada pelayanan yang kurang kilat yang berakibat pada ketidakpuasan pelanggan[3].

Buat menanggulangi kasus tersebut, hingga dibutuhkan sesuatu rancangan sistem data pelayanan kendala listrik yang dapat di akses oleh pegawai PLN yang cocok buat menunjang kelancaran dalam proses tersebut pengolahan informasi komplain tersebut dan aksi perbaikannya. Dengan menggunakan sistem yang diusulkan ini secara benar mungkin hendak mempermudah dalam pengawasan pendistribusian informasi-informasi komplain, sehingga hendak memesatkan proses perbaikannya. Perihal tersebut pula bisa menolong memesatkan penyajian laporan yang akurat, tepat waktu, serta relevan sehingga bisa menolong pihak manajemen dalam mengambil keputusan. Perihal ini bertujuan agar Divisi Technical Support bagian Revisi tidak hadapi hambatan hambatan paling utama dalam pencatatan informasi ataupun memonitoring lamanya waktu pengerjaan kendala lapangan[4].

Dalam praktiknya, revisi kendala kerap terhambat sebab petugas wajib mencari satu persatu informasi yang diperlukan. Untuk menanggulangi permasalahan tersebut hingga dibangunlah sesuatu sistem yang bisa membagikan pemecahan alternatif dalam proses pelayanan kendala listrik serta menyajikan informasi secara terkomputerisasi juga bisa membagikan reminder selaku pengingat untuk revisi. Sehingga seluruh petugas bisa melakukan setiap tugas dengan optimal serta bisa bekerja lebih cepat dalam menjawab pengaduan[5].

Sebuah sistem informasi merupakan kumpulan dari perangkat keras, lunak serta manusia yang akan mengolah dan menggunakan perangkat keras dan lunak tersebut. Informasi merupakan hal yang sangat penting dengan adanya informasi tersebut dapat diketahui kemajuan dan kegagalan proses pelaksanaan. Sistem yang kurang informasi menunjukan bahwa sistem tersebut rapuh. Data merupakan informasi yang diolah supaya berguna bagi yang menerimanya. Definisi sistem secara umum yaitu sekumpulan proses dan seperangkat elemen yang digabung serta dihimpun secara bersama serta saling berintegrasi untuk mencapai suatu tujuan dari organisasi[6].

PHP adalah program aplikasi yang bersifat server side, maksudnya hanya bisa berjalan pada sisi server saja serta tidak bisa berperan tanpa terdapatnya suatu server di dalamnya. PHP juga bukan bahasa pemograman yang lengkap. Artinya program ini tidak menyertakan compiler tertentu yang membuat program hasilnya jadi program. exe yang bisa di jalankan tersendiri. 
PHP merupakan salah satu bahasa pemrograman yang berjalan dalam suatu web server serta berperan sebagai pengolah informasi pada suatu server. Buat membuat web yang dinamis serta gampang buat diperbaharui setiap saat dari browser, diperlukan suatu program yang sanggup mencerna informasi dari pc client ataupun dari pc server itu sendiri sehingga gampang serta aman buat disajikan di browser. Salah satu program yang bisa dijalankan di server serta cukup profesional merupakan PHP. Dengan memakai program PHP, suatu web akan lebih interaktif dan dinamis.

MySQL adalah sebuah perangkat lunak sistem manajemen basis data SQL (bahasa Inggris: database management system) atau DBMS yang multithread, multi-user, dengan sekitar 6 juta instalasi di seluruh dunia. MySQL AB membuat MySQL tersedia sebagai perangkat lunak gratis dibawah lisensi GNU General Public License (GPL), tetapi mereka juga menjual di bawah lisensi komersial untuk kasus-kasus dimana penggunaannya tidak cocok dengan penggunaan GPL Relational Database Management System (RDBMS).

Pada penelitian terdahulu terkait sistem informasi PLN juga sudah diteliti oleh peneliti sebelumnya seperti : Sistem Manajemen Aset PLN berbasis web[7][10], Sistem Manajemen Rasio Elektrifikasi[8], Sistem Inventaris Barang PLN[9], Sistem Keuangan berbasis Web [11].

\section{Metode Penelitian}

\section{Analisa Sistem Yang Sedang Berjalan}

Prosedur merupakan urutan kegiatan yang terdiri dari tahapan-tahapan yang menerangkan mengenai proses apa yang dikerjakan, siapa yang mengerjakan proses tersebut dan bagaimana suatu proses itu dapat dikerjakan. Prosedur pengaduan yang berjalan saat ini adalah sebagai berikut :

1) Pelanggan menghubungi pihak petugas akan keluhan atau pengaduan gangguan dan petugas mencatat data pelanggan tersebut dengan isi keluhannya.

2) Setelah semua data keluhan pelanggan di catat maka dibuatkanlah data-data pengaduan di berikan pihak teknisi.

3) Teknisi menerima data keluhan tersebut dan mulai mengerjakan tugas atau memperbaiki gangguan yang di alami pelanggan.

4) Apabila telah selesai maka teknisi tersebut memberikan laporan bahwa gangguan yang telah diperbaiki statusnya telah selesai (close).

5) Petugas melaporkan atau menginformasikan kembali ke pelanggan bahwa gangguannya telah diperbaiki.

\section{Analisa Sistem Usulan}

Adapun prosedur sistem pengaduan yang di usulkan yang diusulkan adalah sebagai berikut :
1) Pelanggan mengakses web, lalu menginputkan keluhan yang terjadi.

2) Setelah semua data keluhan pelanggan di input maka sistem akan mengeluarkan info data pengaduan, dan admin mengirim kan data tersebut agar bisa di lihat oleh teknisi perbaikan gangguan.

3) Teknisi masuk ke sistem dan dia bisa melihat info pengaduan yang ada bisa mencetak data pengaduan tersebut melalui sistem, dan mulai mengerjakan tugas dari data pengaduan tersebut.

4) Apabila telah selesai maka teknisi mengubah status pengaduan yang di terimanya menjadi done, maka data pengaduan tersebut akan di terima pihak admin.

5) Admin memverifikasi data pengaduan yang telah berstatus done, apabila data keluhan telah benar tanpa gangguan, maka admin mengubah statusnya menjadi close.

6) Maka Admin melaporkan ke pelanggan bahwa gangguan nya telah diperbaiki.

7) Admin juga bisa membuat laporan data data pengaduan perbulan yang isinya adalah data data pengaduan gangguan selama sebulan dan data data pendukung lain seperti rata rata jam gangguan bisa diselesaikan.

\section{Kebutuhan Fungsional Sistem}

Sistem yang sedang berjalan pada PLN Rayon Bangkinang dilihat dari prosedur- prosedurnya yang menjadi bahan evaluasi ialah proses pembuatan data pengaduan serta pemberian laporan pengaduan tersebut yang masih mengandalkan sistem yang manual, serta pembuatan data pengaduannya pun masih manual menggunakan MS Word dan Excel. Ini mengakibatkan tidak efektif dan efisiennya informasi pengaduan gangguan yang dialami oleh pelanggan yang mengakibatkan permintaan pelanggan akan perbaikan gangguan menjadi lama. Dan tidak lupa bagian pembuatan laporan data-data pengaduan gangguan yang telah selesai pun terasa banyak memakan waktu serta riskan akan kesalahan.

\section{Hasil dan Pembahasan}

\section{Perancangan Sistem}

Berdasarkan hasil perancangan, sistem yang dibangun memiliki beberapa class pada class diagram-nya. Detail class dapat dilihat pada Gambar 1. 


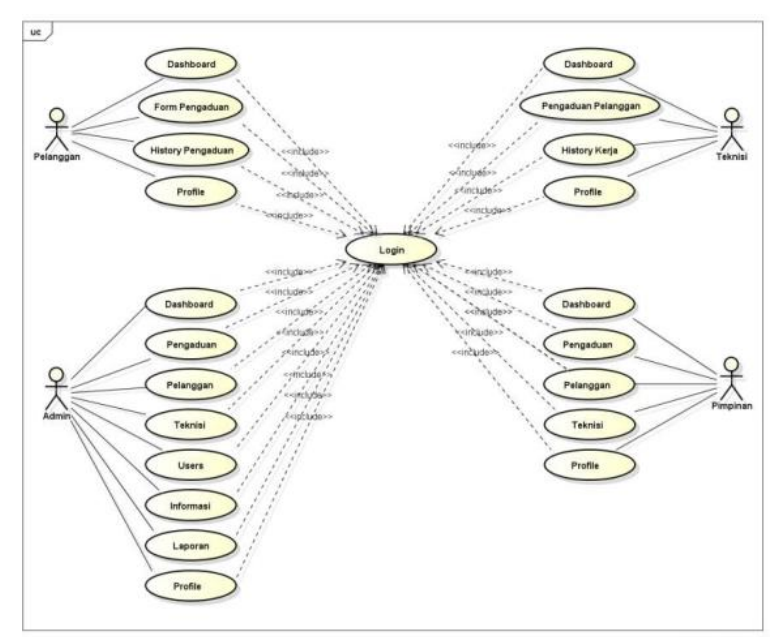

Gambar 1. Usecase Diagram

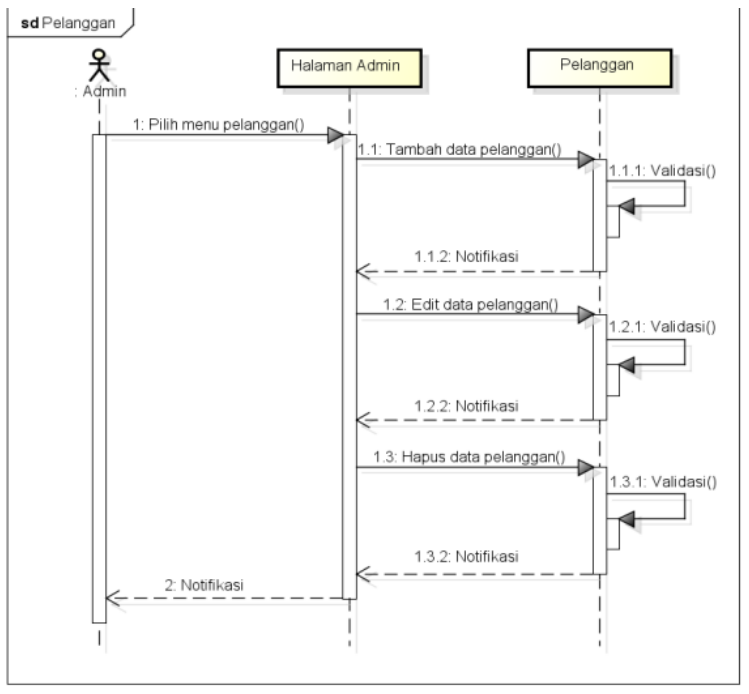

Gambar 2. Sequence Diagram Kelola Pelanggan Admin

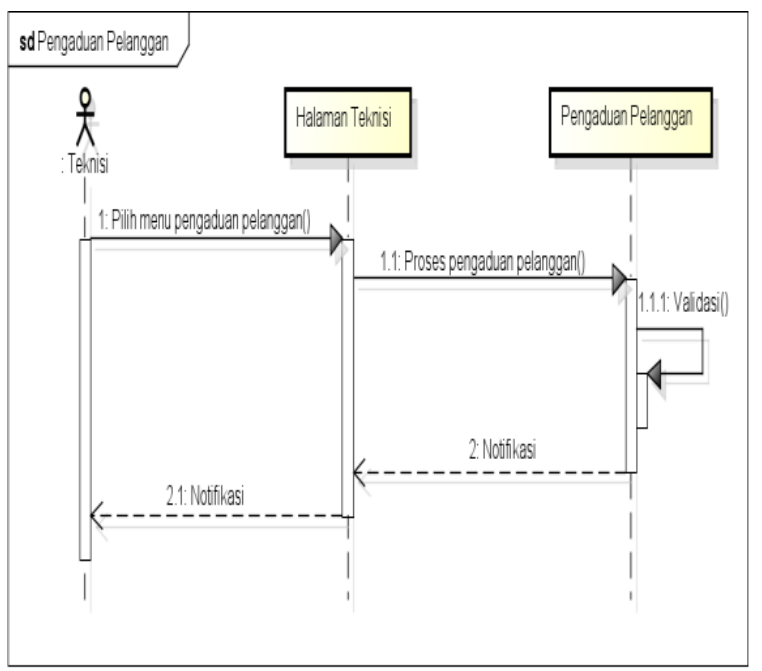

powered by Astah

Gambar 3. Sequence Diagram Kelola Pelanggan Teknisi

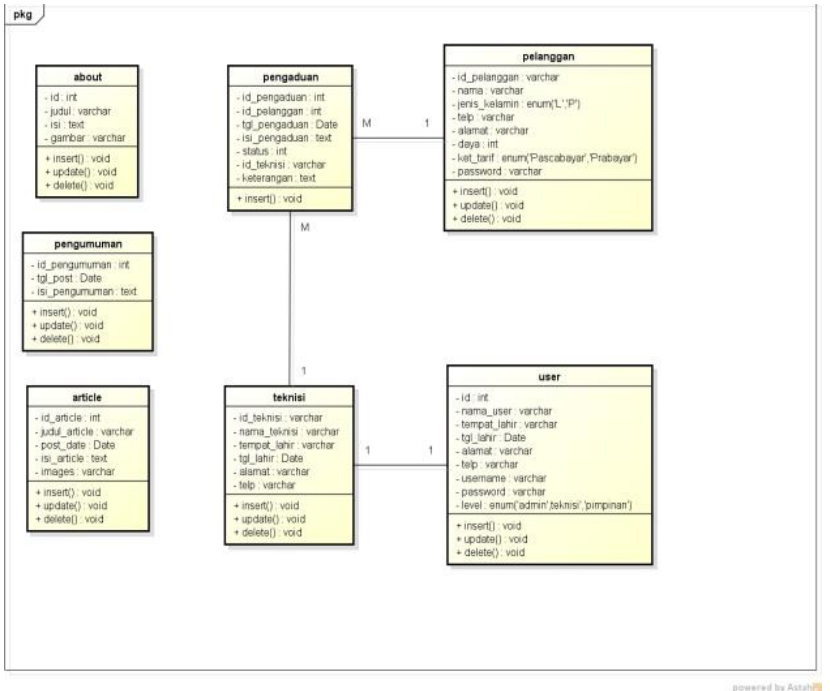

\section{Gambar 4.Class diagram}

\section{Hasil Implementasi Sistem}

Tampilan menu sistem informasi ini terbagi menjadi 4 bagian yaitu:

1) Menu Admin, yang memiliki hak akses akses penuh di dalam sistem.

2) Menu Pelanggan, hak akses untuk masuk ke sistem, menyampaikan kritik dan saran serta menyampaikan keluhan kepada PLN

3) Menu Teknisi, yang memiliki hak akses melihat dan memproses keluhan yang disampaikan admin.

4) Menu Pimpinan, menu yang memiliki hak akses adalah Pimpinan yang memegang kendali untuk melihat laporan.

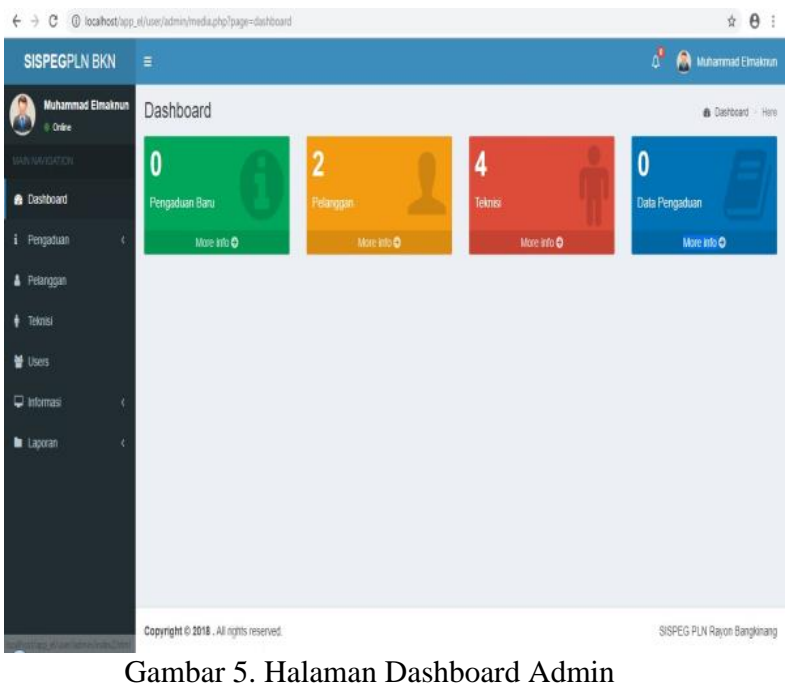

Gambar 5. Halaman Dashboard Admin 


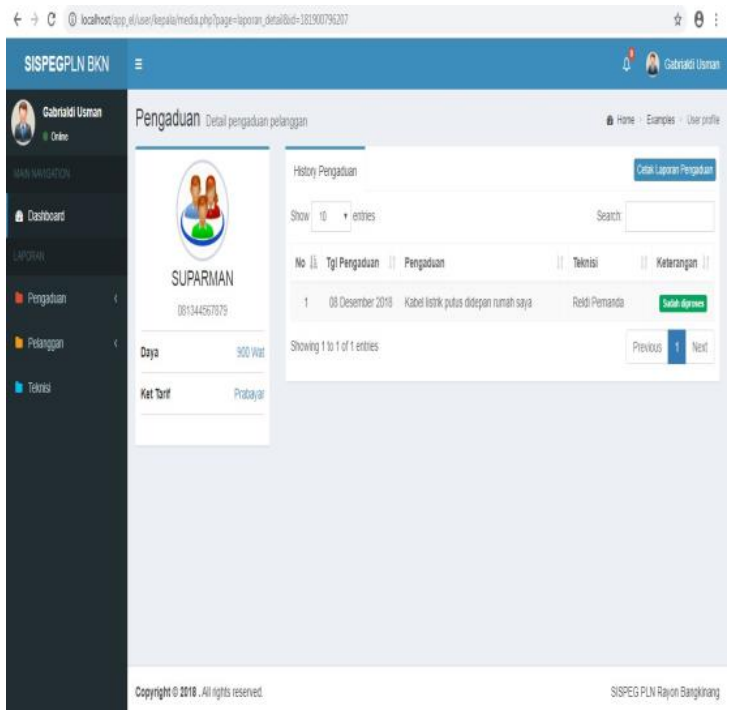

Gambar 6. Detail Pengaduan Pelanggan Admin

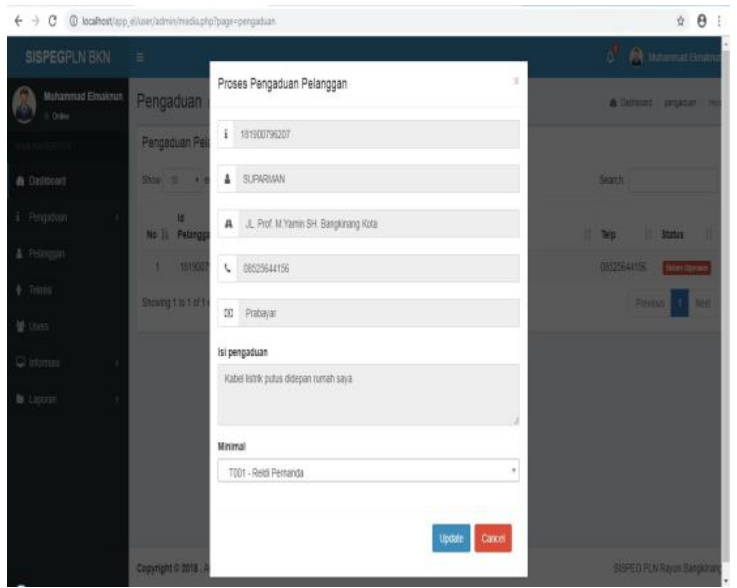

Gambar 7. Halaman Proses Pengaduan Pelanggan

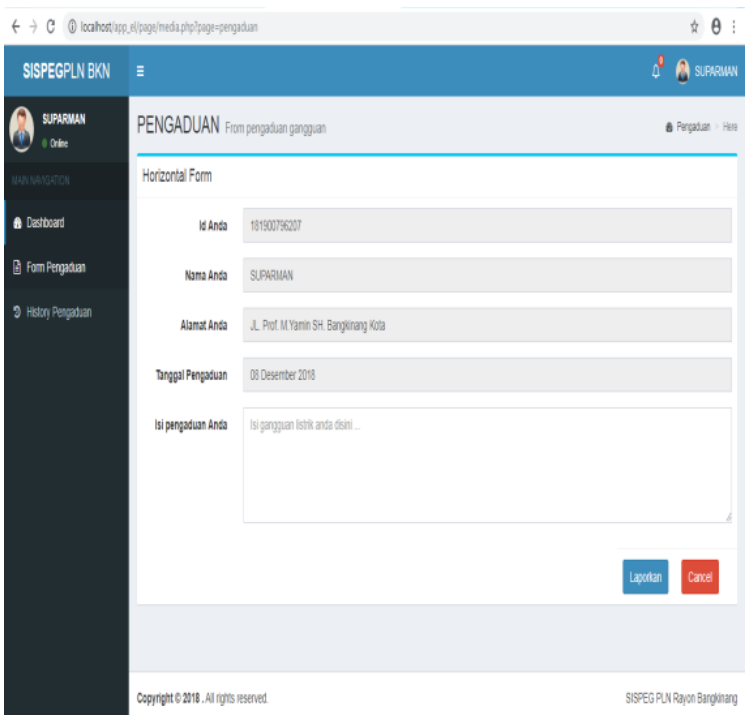

Gambar 8. Halaman Form Pengaduan Pelanggan

\section{Pengujian Sistem}

Pengujian sistem yang digunakan adalah jenis pengujian black box. Jenis pengujian black box adalah dimana proses uji ditampilkan dalam bentuk tabel yang didalamnya menjelaskan tentang deskripsi pengujian, prekondisi awal, prosedur pengujian, data masukkan yang digunakan, keluaran yang diharapkan, kriteria evaluasi hasil, hasil yang didapat dari pengujian dan terakhir kesimpulan pengujian. Teknik yang digunakan untuk melakukan test cases pada sistem yang dibangun ini disebut Functional Analysist

\section{Kesimpulan}

Berdasarkan hasil penelitian yang yang dilakukan pada PLN Rayon Bangkinang, maka dapat ditarik kesimpulan yaitu:

1) Penelitian ini telah berhasil dalam merancang dan membangun sistem informasi Pelayanan Gangguan Listrik PLN Bangkinang.

2) Dengan adanya sistem informasi ini dapat membantu admin dalam mengelola dan mengolah data yang ada.

3) Sistem informasi Pelayanan Gangguan Listrik ini dapat memudahkan pimpinan dalam melihat data laporan yangada sesuai dengan keinginan.

4) Dengan adanya sistem informasi ini dapat memudahkan Pelanggan menyampaikan keluhan pelayanan.

\section{Daftar Pustaka}

[1] Prasetyo, B., Pattiasina, T. J., \& Soetarmono, A. N. (2015). Perancangan dan Pembuatan Sistem Informasi Gudang (Studi Kasus: PT. PLN (Persero) Area Surabaya Barat). Teknika, 4(1), 12-16.

[2] Mesran, M., Huda, N., Hutagalung, S. N., Khasanah, K., \& Iskandar, A. (2018). Sistem Pendukung Keputusan Pemilihan Supervisor Terbaik Pada Bagian Perencanaan Pt. Pln (Persero) Area Medan Menerapkan Preference Selection Index. KOMIK (Konferensi Nasional Teknologi Informasi dan Komputer), 2(1).

[3] Muhaimin, A., \& Raharjo, B. A. (2019). Strategi Humas PLN (Persero) Wilayah Sumatera Selatan, Jambi dan Bengkulu (S2JB) dalam Mengatasi Komplain Masyarakat Terhadap Pemadaman Listrik di Wilayah Palembang. Jurnal Inovasi, 13(1), 11-19.

[4] Gunawan, H., \& Agustian, I. (2014). Aplikasi Pelayanan Gangguan Listrik Berbasis Web Di Pln Rayon Banjaran. Jurnal Informasi, 6.

[5] Irfan, D., Agustin, A., \& Hediyati, S. (2020). Aplikasi Pengukur Tingkat Sentimen 
Jurnal Sains, Teknologi dan Industri, Vol. 18, No. 1, Desember 2020, pp.57 - 62 ISSN 2407-0939 print/ISSN 2721-2041 online

Pelanggan Berdasarkan Komplain Pelanggan Pln Menggunakan Algoritma K-Nearest Neighbor. INOVTEK Polbeng-Seri Informatika, 5(2), 332-346.

[6] Iskandar, D. (2015, July). Sistem Informasi Gardu Induk dan Gardu Distribusi PLN. In Seminar Nasional Informatika (SEMNASIF) (Vol. 1, No. 2).

[7] Sahrun, N. (2018). Sistem Informasi Manajemen Aset Perusahaan Listrik Negara (PLN) Berbasis Web pada Rayon Kuala Enok Kabupaten Indragiri Hilir. INTEGER: Journal of Information Technology, 3(2).

[8] Yusuf, F., \& Rahayan, R. (2018). Sistem Monitoring Rasio Elektrifikasi Di PT PLN (Persero) Wilayah Sulselbar Berbasis Web. Jurnal Insypro: Information System and Processing, 3(1), 1-10.

[9] Huda, N., \& Amalia, R. (2020). Implementasi Sistem Informasi Inventaris Barang pada PT. PLN (Persero) Palembang. Jurnal Sisfokom (Sistem Informasi dan Komputer), 9(1), 13-19.

[10] Wijayanti, A., \& Firdaus, M. I. B. (2017). Sistem Monitoring Perbaikan dan Perawatan Fasilitas PT. PLN Di Kabupaten Tuban Berbasis Web GIS. INOVTEK Polbeng-Seri Informatika, 2(1), 57-63.

[11] Toar, E., Nintias, I., \& Bawole, C. (2020). Sistem Informasi Keuangan Berbasis Web Pada PT PLN UP3 Kotamobagu. JointerJournal of Informatics Engineering, 1(02), 3743. 